BNL-107822-2015-JA

\title{
Considering the total cost of electricity from sunlight and the alternatives
}

\author{
Vasilis Fthenakis \\ Brookhaven National Laboratory and Columbia University
}

Photovoltaic (PV) electricity generation has grown to about $17 \mathrm{GW}$ in the United States, corresponding to one tenth of the global capacity. Most deployment in the country has happened during the last 6 years. Reflecting back in time, in early 2008 this author and his collaborators James Mason and Ken Zweibel, published in Scientific American and in Energy Policy a Solar Grand Plan demonstrating the feasibility of renewable energy in providing $69 \%$ of the U.S. electricity demand by 2050 , while reducing CO2 emissions by $60 \%$ from 2005 levels; the PV contribution to this plan was assessed to be $250 \mathrm{GW}$ by 2030, and 2,900 GW by 2050 [1]. The DOE's more detailed SunShot vision study, released in 2012, showed the possibility of having $300 \mathrm{GW}$ of PV installed in the United States by 2030 , and $630 \mathrm{GW}$ by 2050.

Assessing the sustainability of such rapid growth of photovoltaics necessitates undertaking a careful analysis because PV markets largely are enabled by its promise to produce reliable electricity with minimum environmental burdens. Measurable aspects of sustainability include cost, resource availability, and environmental impact. The question of cost concerns the affordability of solar energy compared to other energy sources throughout the world. Environmental impacts include local-, regional-, and global-effects, as well as the usage of land and water, which must be considered in a comparable context over a long time, multigenerational horizon. Finally, the availability of material resources matters to current- and future-generations under the constraint of affordability. More concisely, PV must meet the need for generating abundant electricity at competitive costs while conserving resources for future generations, and having environmental impacts much lower than those of current modes of power generation, preferably lower than those of alternative future energy options.[2]

These challenges vary between different photovoltaic technologies. For example, first-generation crystalline-silicon photovoltaics rely on abundant silicon, but their production costs are relatively high. By comparison, second-generation technologies can be produced more cheaply, but they use materials of limited availability. Cadmium telluride thin-film modules, for example, are the cheapest to produce, but there are concerns about the future availability of tellurium, and about the toxicity of cadmium used as a precursor to $\mathrm{CdS}$ and CdTe. Similarly, there are concerns about the availability of materials for copper indium gallium (di)selenide (CIGS) technologies (i.e., gallium, indium), and its toxicity (i.e., cadmium, selenium) and furthermore, some high-performance silicon technologies use potent greenhouse gases for reactor cleaning (e.g., NF3).[3] However, all current commercial PV technologies carry one very important existential attribute that often is neglected in discussions of energy policy ; viz., 
by displacing conventional fossil-fuel-based power generation, they prevent a spectrum of acute- and chronic-health and environmental impacts that carry a great economic cost to society as a whole.

The costs of photovoltaic modules have fallen by a factor of three over the last five years, and the system costs in several South European regions, the U.S. Southwest, and in South America have been reduced to levels of cost parity with electricity from conventional fuel-based power plants. Such parity throughout the United States is expected to be evident by 2040 or earlier. However, for the near-term, cost grid parity is a moving target as the price of fossil fuels has been falling due to the increased supply of natural gas obtained by fracking. I believe that a holistic approach in cost analysis is needed, including external burdens (e.g., environmental, water resources) in addition to direct costs. If external costs were included in the bids of the energy suppliers, solar energy would compete more fairly with fossil-fuel power-generators. Highlighting and monetizing the environmental- and security-advantages of solar energy can justify implementing public policies towards developing it. Different examples of successful policies in the world towards this solar-energy goal share a common trait; such policy instruments are implemented through long-term incentive programs. In that sense, U.S. policy-makers need to identify the right mix for promoting solar energy, while sustaining social- and political-support for it. To ensure sustained growth, especially beyond 2017 when the investment tax credit (ITC) program for solar projects is scheduled to expire, investors should be given a variety of incentives for increasing the use of solar energy, including credits for displacing $\mathrm{CO} 2$ and toxic emissions in power generation.

Often missing from the literature is the identification of barriers for developing solar energy, and of clear policy guides to ensure uninterrupted growth in deploying solar power. The Renewable Portfolio Standards (RPS), the SunShot efforts to decrease the soft costs of PV (e.g., administrative and permitting), and the EPA's new rules on power-plant emissions are steady steps in the right direction. In addition, full cost accounting of energy life-cycles should be implemented in evaluating scenarios of sustainable energy development. Monetization of the external costs of energy life-cycles, including those of photovoltaics (PV) can be based on the well-documented damage factors published by the National Research Council, the Harvard School of Public Health, and others. These studies show the greatest health- and environmental-effects in the life-cycle of coal-power generation are those from toxic air-pollutants during combustion, followed by the impacts of mining, and greenhouse gas emissions (GHG emissions). Carbon-dioxide capture with carbon sequestration (CCS) is advocated widely as enabling the continuation of coal burning for power generation, but CCS , while reducing GHG emissions, will lead to increases of toxic emissions and health-, safety-, and environmental-(EHS) impacts in mining regions, as coal consumption per unit of electricity output would increase. The same

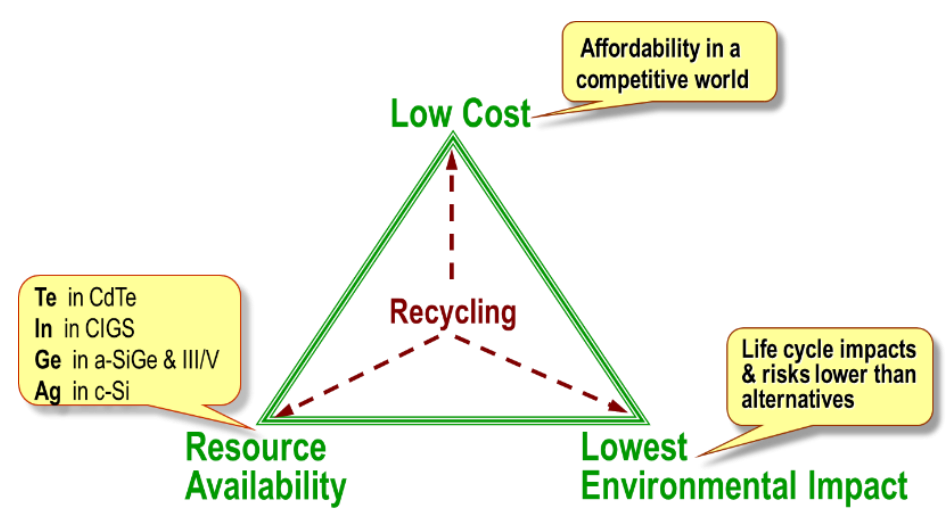
applies to the proliferation of natural gas from gas-shale resources, as hydraulic fracturing increases the impacts of extracting gas on both the air- and water-pathways, and conversion to LNG for exportation further increases the upstream health- and environmentalimpacts and risks. These factors can be 
readily introduced into models of energy-environmental-economic analysis (e.g., NEMS, MARKALMACRO) used in national electricity projections.[4]

Resource availability is another basic metric of availability; in this context, I consider materials, fuels, land, and water. The availability of Te, In, Ge, and Ga indeed constrains the production of CdTe and CIGS photovoltaics. However, several comprehensive assessments have shown that there are sufficient resources to bring each of these technologies to Terawatt production by midcentury; if recycling is widely adopted, such production can reach up to 10 TW by the century's end [2]. Recycling the end-oflife photovoltaics is becoming increasingly important as PV deployment grows. It helps in keeping the material costs low as it provides significant secondary resources at a price lower than the primary ones, it displaces energy from material production, and it resolves concerns about potential environmental contamination from the uncontrollable disposal of PV.

Fig.1. The three pillars of PV sustainable growth

Processing solar materials, manufacturing devices, and installing systems require energy, most of which is provided by fossil fuels. The energy payback times (EPBTs) of current photovoltaic power plants is between 0.5 - to 2-years, depending on the radiation in the place of installation, and the type of technology used; this is a two-order of magnitude improvement from the EPBT of the early (1970) systems $[5,6]$. This corresponds to a 15 - to 60 -fold energy return on energy investment (EROEI), saving a tremendous amount of fossil fuel for building a new infrastructure (e.g., PV modules, power electronics, grid extension, storage systems) to enable the transition to a carbon-free society. Recycling would further improve the EPBT and the EROEI of PV because recycling glass, aluminum, tellurium, and other semiconductor materials requires only a fraction of the energy consumed in their primary production and, consequently, it produces only a fraction of green-house emissions (GHG).

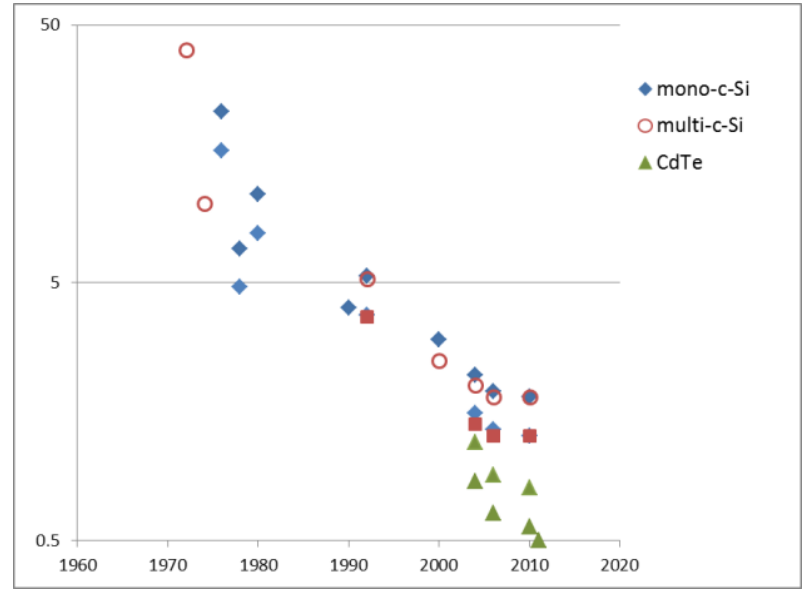

Fig. 2. Historical evolution of Energy Payback Times (EPBT)
Utility-scale ground-mount PV power plants occupy a large amount of land (5-8 acres per MW); this sometimes is presented as constraining the largescale deployment of photovoltaics. Here, comparative life-cycle assessment is instructive. When accounting for the land use in the "cradle-tograve" life cycle of photovoltaics and coal-based power generation in the United States, the first uses less land than does the second. [7] Most of the use of coal land is in surface mining, which in addition to occupying land, also damages and often contaminates it. 
Water availability has emerged as a great challenge in power generation as fossil-fuel-based thermoelectric power generation requires vast amounts of water. Generating PV electricity does not require water in sharp contrast to generating thermoelectric power thereby alleviating the challenge of generating power in regions of increasing aridity.

The third pillar of sustainability of an electricity infrastructural transformation based at large on solar energy, is for this transformation not to cause any adverse environmental effects. Although operating photovoltaic systems do not generate any toxic- or greenhouse- gases, such emissions occur during the production of the materials used for solar cells and systems. Recent assessments of the life-cycle emissions from photovoltaics showed that, under conditions equivalent to those in the southwestern United States, they emit about 17-39 g of CO2/kWh, compared to 500-1100 g of CO2/kWh from fossilfuel plants, and 16-55 g of $\mathrm{CO} 2 / \mathrm{kWh}$ during the life cycles of U.S. nuclear-power plants [6]. Releases of priority pollutants (e.g., SO2, NOx, particulates) from photovoltaic life-cycles comprise, like their greenhouse gas emissions, only $2-4 \%$ of those from fossil-fuel plants. Replacing grid electricity with PV systems would result in an 89-98\% reduction in the emissions of greenhouse gases, criteria pollutants, heavy metals, and radioactive species. However, the end-of-life of photovoltaics would generate a significant amount of solid waste (about 100 tonnes per MW of decommissioned PV modules) unless materials are recovered and reused.

It is widely recognized that recycling used PV modules is necessary to prevent environmental pollution. In Europe, the PV industry adopted a proactive approach that served them well during the transition to, a soon to be required, compliance with Waste Electrical and Electronic Equipment (WEEE) regulations. Germany's Electrical and Electronic Equipment Act (ElectroG) requiring collection and recycling of Electrical and Electronic Equipment (EEE) will be extended to PV in middle 2015 and is expected to become a global standard. The United States lacks a national policy and the necessary infrastructure to mandate PV recycling. Environmental regulations can determine the cost and complexity of dealing with end-of-life PV modules. If they were characterized as "hazardous", then special requirements for material handling, disposal, record keeping, and reporting would escalate the cost of decommissioning modules.[8]

Currently, there are well-tested technical solutions (separation and material recovery processes) for c-Si (wafer based) and CdTe PV products, but not for other technologies. Several R\&D recycling projects are being carried out in Europe that include recycling CIGS PV. There is a need for comprehensive evaluations of current- and new-recycling technologies using life-cycle assessment, life-cycle costing, and cost-benefit assessments. Technical- and economic-evaluations should include the treatment of unrecovered materials, solid waste, liquid discharges, and air emissions from recycling operations. The potential of specific recycling processes to apply to various PV module and component types also should be assessed. Such studies can guide the standardization of encapsulation materials and recycling methods, and potentially reduce the life-cycle cost of PV.

The most impactful action that industries involved in PV recycling could take is to assume Extended Producer Responsibility (EPR) following the European initiative. Recycling could become economically profitable if the cost of collecting and transporting of PV modules is minimized through an industry 
collective operation, and the recovery of materials is optimized, for example, by recovering pure glass for reuse in the form of glass culets into the circuits of soda-lime glass production. Life-cycle analysis (LCA) of recycling operations that account for all emissions and material and energy inputs would guide potential innovations in PV processes, product design, and recycling to minimize all cradle-to-grave lifecycle impacts. Undoubtedly, full-cost accounting of PV in comparison to other power generation technologies also would show that recycling is "profitable" for society at large.

Looking into the future, the cost competitiveness of photovoltaics is assured if a long-term energy policy includes a serious commitment to decarbonization of our economy. Their increasing deployment will continue to lower costs, whilst the realization and monetization of health- and environmental- benefits will have a strong positive feedback into their further deployment and price reduction. When PV with large- scale storage reach cost-grid parity, which we forecast could start by 2020, the deployment of solar-energy system can accelerate, especially after 2030 when the current infrastructure would be phased-out. The energy return on investment (EROEI) of PV will continue rising as the efficiencies of photon-to-electron conversion and of material utilization improve. Recycling end-of-life systems then becomes an important aspect of sustainability and needs to be optimized to help rather than hinder the affordability of photovoltaics systems.

\section{References}

1. Fthenakis V. Mason J. and Zweibel K., The Technical, Geographical and Economic Feasibility for Solar Energy to Supply the Energy Needs of the United States, Energy Policy, 37, 387-399, 2009.

2. Fthenakis V.M., Sustainability metrics for extending thin-film photovoltaics to terawatt levels. MRS Bulletin, 37(4), 425-430, 2012

3. Fthenakis V., Overview of Potential Hazards, Chapter V-1, pp.857-868, in Practical Handbook of Photovoltaics: Fundamentals and Applications, (Editors: T. Markvart and L. Gastaner), Elsevier, 2003.

4. Morris S.C., Goldstein G.A., Fthenakis V.M., NEMS and MARCAL-MACRO models for energyenvironmental-economic analysis, Environmental Modeling and Assessment, 7, 207-216, 2002.

5. Fthenakis V., Raugei M., Held M., Kim H. C., Krones J. An update of Energy Payback Times and Greenhouse Gas emissions in the Life Cycle of Photovoltaics, Proceedings 24th European Photovoltaic Solar Energy Conference, Hamburg, Germany, 21-25 September 2009.

6. Fthenakis V.M. and Kim H.C., Photovoltaics: Life-cycle analyses, Solar Energy, 85, 1609-1628, 2011.

7. Fthenakis V.M., and Kim H.C, Land Use and Electricity Generation: A Life Cycle Analysis, Renewable and Sustainable Energy Reviews, 13, 1465-1474, 2009.

8. Fthenakis V.M, Eberspacher C., and Moskowitz P.D., Recycling Strategies to Enhance the Viability of CIS Photovoltaics, Progress in Photovoltaics: Research and Applications; 4, 447-456, 1996. 
